\title{
The fate of the peroxyl radical in autoxidation: How does polymer degradation really occur?
}

\author{
Leesa M. Smith $\neq$, Heather M. Aitken $\neq$, Michelle L. Coote*
}

ARC Centre of Excellence for Electromaterials Science, Research School of Chemistry, Australian National University, Canberra ACT 2601, Australia 


\section{CONSPECTUS}

Bolland and Gee's Basic Autoxidation Scheme (BAS) for lipids and rubbers, has long been accepted as a general scheme for the autoxidation of all polymers. This scheme describes a chain process of initiation, propagation, and termination to describe the degradation of polymers in the presence of $\mathrm{O}_{2}$. Central to this scheme is the conjecture that propagation of damage to the next polymer chain occurs via hydrogen atom transfer with a peroxyl radical. However, this reaction is strongly thermodynamically disfavored for all but unsaturated polymers, where the product allylic radical is resonance stabilized. Paradoxically, there is no denying that the autocatalytic degradation and oxidation of saturated polymers still occurs. Critical analysis of the literature, described herein, has begun to unravel this mystery.

One possibility is that the BAS still holds for saturated polymers but only at unsaturated defect sites, where H-transfer is thermodynamically favorable. Another is that peroxyl termination rather than H-transfer is dominant. If this were the case, tertiary peroxyl radicals (formed at quaternary centers or quaternary branching-defects) may terminate to form alkoxy radicals, which can much more readily undergo chain transfer. This process would lead to the creation of hydroxy groups on the degraded polymer. On the other hand, primary and secondary peroxyl radicals would terminate to form non-radical products and halt further degradation. As a result, under this scenario the degree of branching and substitution would have a major effect on polymer stability. Herein, we survey studies of polymer degradation products, and of the effect of polymer structure on stability, and show that indeed peroxyl termination is competitive with peroxyl transfer and possibly dominant under some conditions. 
It is also feasible that oxygen may not be the only reactive atmospheric species involved in catalyzing polymer degradation. Herein we outline plausible mechanisms involving ozone, hydroperoxyl and hydroxyl radicals that have all been suggested in the literature and can account for the experimentally observed formation of hydroperoxides without invoking peroxyl transfer. We also show that oxygen itself has even reported to slow the degradation of poly(methyl methacrylates), which might be expected if peroxyl radicals are unreactive to hydrogen transfer. Discrepancies between the rate of oxidation and the rate of degradation have been observed for polyolefins and also support the notion that oxygen, counterintuitively, stabilizes these polymers against degradation. We show that together these studies support alternative mechanisms for polymer degradation.

A thorough assessment of kinetic studies reported in the literature indicate that they are limited by their propensity to use models based on the BAS disregarding the chemical differences intrinsic to each class of polymer. Thus, we propose that further work must be done to fully grasp the complex mechanism of polymer degradation in ambient conditions. Nonetheless, our analysis of the literature points to measures that can be used to enhance or prevent polymer degradation and indicates that we should focus beyond just the role of oxygen - toward the specific chemical nature and environment of the polymer at hand.

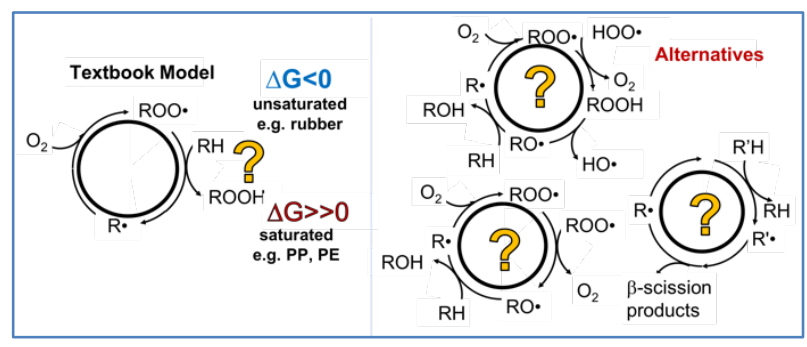




\section{INTRODUCTION}

The presence of oxygen, light, heat and reactive species is known to compromise the structure of polymers and affect their mechanical performance, appearance and lifetimes. Understanding the mechanisms involved in the degradation of polymers is crucial in improving their resistance to environmental factors, and in understanding how to design accelerated aging studies which are reflective of chemical conditions found in the environments in which they are to be used. ${ }^{1}$

The investigations of Bolland and Gee ${ }^{2-7}$ were the basis for their proposed Basic Autooxidation Scheme (BAS). Key to this scheme is its radical chain nature (Scheme 1). Covalent bond homolysis to radicals that may undergo further rearrangement and bond cleavage (e.g. betascission) requires substantial energy. As such, if degradation of each molecule required a separate bond homolysis, degradation would be a slow and steady process. However, most materials degrade autocatalytically and more rapidly than expected. It is proposed that this is because the radicals are capable of undergoing chain transfer processes in which they abstract a hydrogen from another molecule - becoming non-radicals in the process and transferring the radical center to a new chain. In this way, one initiation event can damage not just one chain, but many before ultimately combining with other radicals to form closed-shell species. 


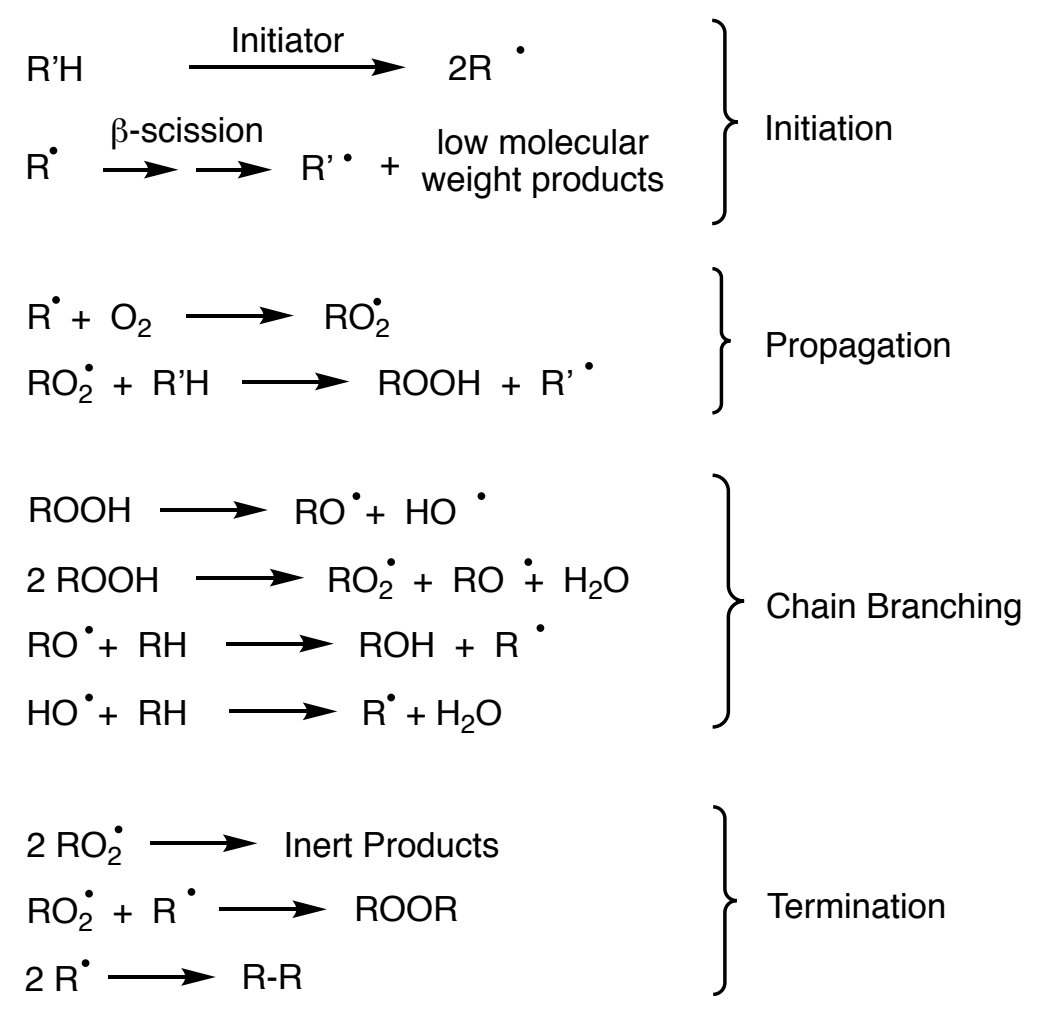

Scheme 1. Basic Autoxidation Scheme

The original autooxidation scheme was derived for lipids and rubbers, ${ }^{2-7}$ which contain $\mathrm{C}=\mathrm{C}$

bonds. Thus, there is the possibility of peroxyl radicals, $\mathrm{ROO}$, abstracting an allylic hydrogen to form a radical of the form $-\mathrm{CH} \bullet-\mathrm{CH}=\mathrm{CH}-.^{8}$ As this product radical is highly resonance stabilized, this reaction is both thermodynamically and kinetically favorable. However, this same mechanism has been almost universally assumed to apply to all polymers. ${ }^{9,10}$ Recently we showed that for most other polymers this reaction is strongly thermodynamically disfavored because the product carbon-centered radical is less stable than the attacking peroxyl radical (Figure 1). ${ }^{11}$ In our original study we suggested that those polymers undergo autooxidation only because they contain small concentrations of double bonds as chain ends or defect structures. ${ }^{11}$ This has the important implication that one might be able to stabilize polymers by eliminating or preventing these defect structures from forming through changes to the reaction conditions. 


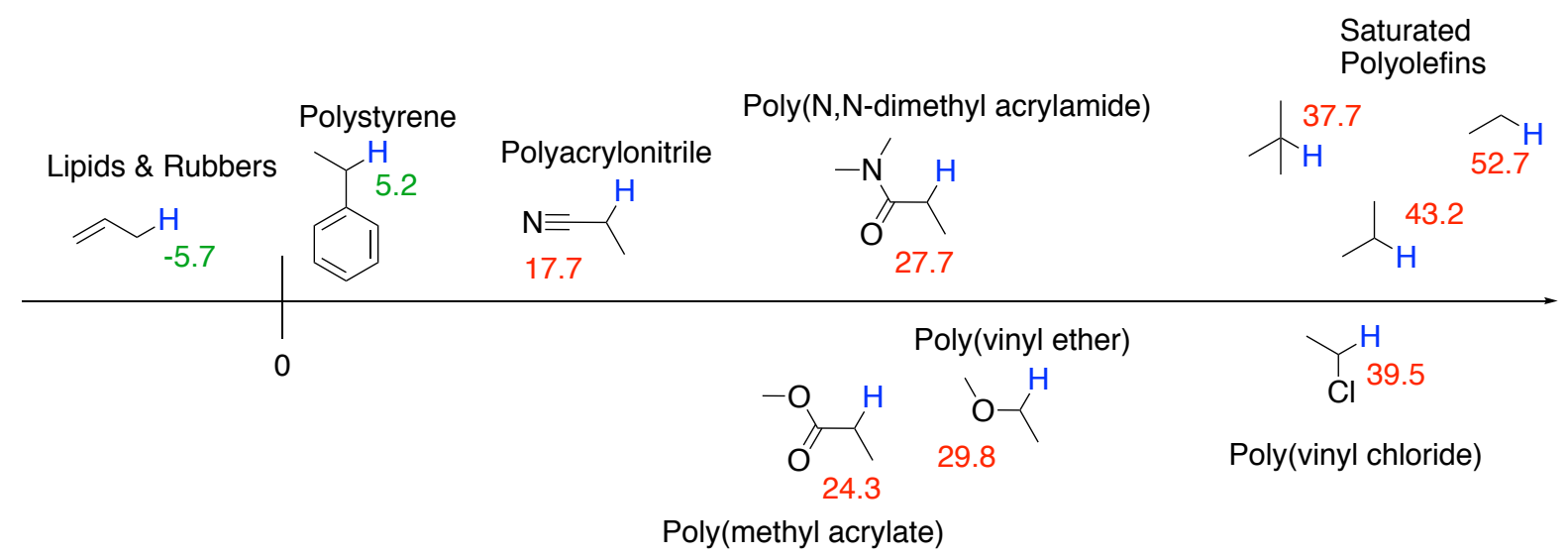

Figure 1. Reaction enthalpy $\left(298 \mathrm{~K}, \mathrm{~kJ} \mathrm{~mol}^{-1}\right)$ for model hydrogen abstraction reactions of the form $\mathrm{ROO} \bullet+\mathrm{H}-\mathrm{R} \rightarrow \mathrm{ROOH}+\mathrm{R} \bullet($ Data taken from Ref 11$)$

However, our original results were based on thermodynamics only. In a complicated multistep process, it is possible for a thermodynamically disfavored process to occur, provided the products are quickly and irreversibly removed. In the case of autoxidation, an obvious downstream reaction is the rapid and irreversible trapping of the product $\mathrm{R} \bullet$ radical by $\mathrm{O}_{2}$ to form $\mathrm{ROO} \bullet$ which can perform the next hydrogen abstraction. If this $\mathrm{O}_{2}$ addition reaction is responsible for driving the propagation of autoxidation, one might surmise that autoxidation is faster in the presence of $\mathrm{O}_{2}$. However, if these peroxyl radicals are unreactive to hydrogen transfer with saturated chains, then the opposite would be true: trapping of $\mathrm{R} \bullet$ formed by homolysis or beta-scission by $\mathrm{O}_{2}$ would slow autoxidation. Clearly establishing which scenario is correct, and under what conditions, is important for designing optimal polymer stabilization strategies.

Moreover, if the peroxyl radical is unreactive to hydrogen transfer, how does it react instead? An obvious pathway is through bimolecular peroxyl radical termination. Interestingly, the consequences of this reaction are very different for ROO• formed from tertiary $\mathrm{R} \bullet$ versus 
primary or secondary $\mathrm{R} \bullet .{ }^{12}$ In the former case, the predominant products are highly reactive $\mathrm{RO} \bullet$ radicals that are capable of undergoing hydrogen transfer with saturated polymer chains, in the latter the predominant products are stable non-radicals. Hence, if peroxyl termination occurs, the structure of $\mathrm{R} \bullet$ determines whether it is chain breaking or not.

While it is clear that the propagation step in BAS is thermodynamically unfavorable for most polymer classes, it is unclear how to reconcile this with the observation that auto-oxidation nonetheless occurs and hydroperoxides are frequently observed. Ascertaining the correct mechanism has important implications for the design of stable polymers, or conversely, polymers that readily degrade. In this account we will critically evaluate the literature with a view to answering the following questions:

1. Is the textbook autooxidation scheme wrong for cases where the ROO• hydrogen abstraction step is disfavored thermodynamically - or does some downstream reaction drive it forward? Does this change with conditions?

2. Is autoxidation made possible by defect structures and what is the relationship between defect concentration and polymer lifetime for specific systems?

3. In the absence of defect structures are there any other propagation mechanisms that need to be considered?

4. Does oxygen stabilize or destabilize polymers?

5. Are there other reactive oxygen species that need to be considered?

In this way, we will attempt to provide a more complete picture of autoxidation, along with recommendations for stabilizing polymers. 


\section{DEFECT STRUCTURES}

In a degrading material, peroxyl radicals form rapidly from the addition of oxygen to carboncentered radicals. In the standard BAS mechanism, it is proposed that these peroxyl radicals are consumed by hydrogen transfer reactions with fresh polymer chains. While this reaction is thermodynamically favored for the allylic hydrogens in polymers containing unsaturated groups, it is strongly disfavored for fully saturated chains. ${ }^{11}$ If this reaction is also kinetically disfavored, then the obvious alternative reaction channel of peroxyl radicals is their bimolecular termination. This is chain-breaking if the peroxyl radicals ROO• are formed from primary or secondary $\mathbf{R}^{\bullet}$, whereas it generates highly reactive alkoxy radicals, $\mathrm{RO} \bullet$, if $\mathrm{R} \bullet$ is tertiary. ${ }^{12}$ Thus, one can envisage the impact that polymer structure has on its susceptibility to degradation (as seen in Scheme 2). It is also worth noting that, depending on diffusion rates, an alternative reaction channel for the peroxyl radicals is their unimolecular $\beta$-scission to form carbon-centered radicals, which could also more easily abstract hydrogen than peroxyls.

Standard BAS
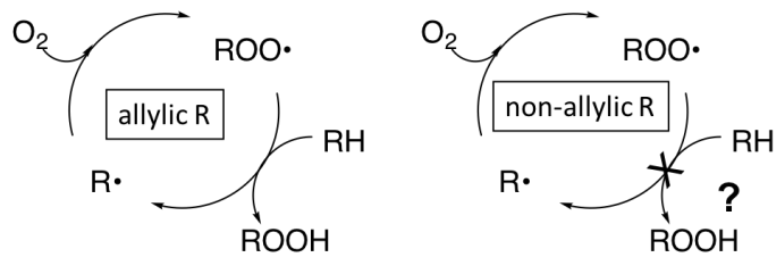

Peroxyl
Termination
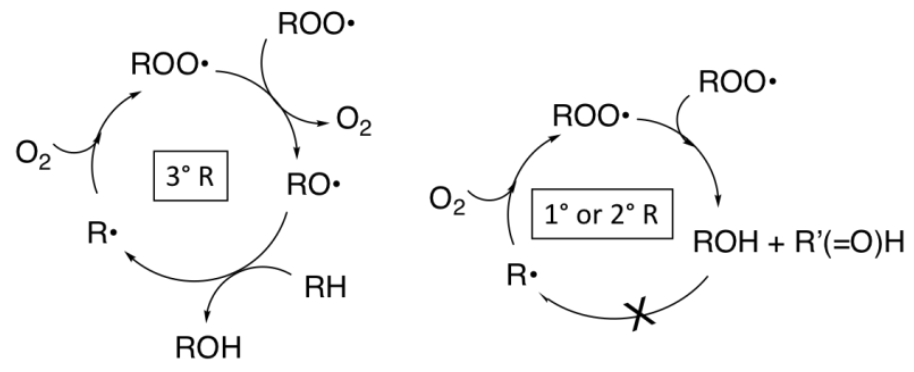
Scheme 2. Reaction channels of the peroxyl radical and their dependence on polymer structure.

Unsaturated groups may arise during polymerization, degradation and curing. Chain termination reactions in free radical polymerization processes form unsaturated end groups by disproportionation reactions, while in ionic and coordination-catalyzed polymerization they form through beta-H or beta- $\mathrm{CH}_{3}$ transfer. Beta-scission during free radical polymerization may also form unsaturated linkages during the reaction. Labile chlorine substituents in PVC contribute to midchain unsaturated linkages by elimination during and after polymerization. ${ }^{13}$ Polyesters and polyamides do not form unsaturated end groups during polymerization, however they can occur as a result of cis-elimination during high-temperature curing processes. ${ }^{14}$ In all cases, the presence of unsaturated groups would be enough to promote peroxyl abstraction in an otherwise saturated polymer chain. ${ }^{11}$

It is well known that rubbers undergo rapid environmental degradation, while saturated plastics have much longer lifetimes under the same conditions. For saturated plastics such as polypropylene (PP), ${ }^{15}$ polyethylene (PE),${ }^{16,17}$ polyisobutylene (PIB),${ }^{18}$ poly(methyl methacrylate) (PMMA), ${ }^{19,20}$ and poly(vinyl chloride) (PVC) $)^{21,22}$ studies have shown that degradation increases as the concentration of unsaturated groups increases. Unfortunately, many of these studies used Thermal Gravimetric Analysis (TGA) or Differential Calorimetric Spectroscopy (DSC), which involves heating the polymer to very high temperatures over short periods with a constant heating rate, while detecting mass loss (TGA) or heat flow (DSC). Aside from being a poor reflection of ambient degradation conditions, the rapid temperature scan rate (typically $1-2{ }^{\circ} \mathrm{C}$ $\min ^{-1}$ ) means that initiation is primarily studied. 
A better approach is to subject the polymer samples to weathering experiments under more realistic conditions, and analyze them for mass loss and degradation products. Barner-Kowollik and co-workers conducted a series of accelerated ageing experiments ${ }^{20,23}$ in which acrylic polymers, such as PMMA, were heated to $95^{\circ} \mathrm{C}$ and exposed to high $\mathrm{UV}$ radiation $\left(1 \mathrm{~kW} \mathrm{~m}^{-2}\right)$ in an ambient atmosphere. Each polymer was functionalized to have either fully saturated, unsaturated or epoxidized end-groups. Subsequent mass spectrometry (MS) analysis, suggested that saturated end groups protected the polymer samples from degradation. In another example Gardette and Lemaire ${ }^{22}$ studied the oxidation of PVC. The rate of degradation at $100^{\circ} \mathrm{C}$ was found to increase after pretreatment at $140^{\circ} \mathrm{C}$ to increase polyene concentration. Pazur and Petrov $^{18}$ further compared PIB with PIB/isoprene copolymers, finding that thermo-oxidation below $70^{\circ} \mathrm{C}$ was much slower for (saturated) PIB, and increased with the concentration of (unsaturated) isoprene in the copolymer. Accelerated ageing studies of PE have also observed that unsaturated groups increase degradation. ${ }^{24}$

If bimolecular peroxyl termination is a dominant pathway then the level of substitution of the degrading polymer radical determines whether peroxyl termination is chain breaking or not. Thus, it is important to consider whether quaternary repeat units or defects in the polymer, make a significant difference to degradation (see Scheme 2). Whilst evidence remains unclear, studies of the thermo-oxidation of (quaternary) $\mathrm{PIB}^{25,26}$ below $100^{\circ} \mathrm{C}$ suggest that oxidation is faster compared to similar studies of (secondary) $\mathrm{PE}^{16,17}$ and (tertiary) PP..$^{15,27}$ Degradation of PVC is also known to be accelerated by branching ${ }_{13}^{13}$ however given that these branches are typically at labile chlorines, initiation would also be affected. 


\section{ROLE OF OXYGEN}

Under the BAS, oxidation, as measured by concentration of $\mathrm{HOO}$ groups on the polymer, is first order with respect to oxygen concentration..$^{28}$ Linear relationships between these two concentrations are frequently cited as evidence for the BAS..$^{29}$ Moreover, the dependence on $\mathrm{O}_{2}$ concentration is reinforced by the need for $\mathrm{O}_{2}$ diffusion corrections in BAS kinetic models. ${ }^{30}$ Oxidation must, fundamentally, involve $\mathrm{O}_{2}$ or some other oxidant. The real question is whether polymer degradation (as measured in terms of reduction in molecular weight and loss of mechanical properties), is faster in the presence or absence of $\mathrm{O}_{2}$. Under the standard BAS, one would expect thermodynamically unfavorable peroxyl transfer reactions to be driven kinetically by trapping with oxygen. However, if this trapping reaction is not sufficient to drive peroxyl transfer, formation of unreactive peroxyl radicals may slow degradation. In the absence of oxygen, $\mathrm{R} \bullet$ radicals will abstract hydrogen from the next polymer chain, a reaction that is more kinetically and thermodynamically favoured than abstraction by a peroxyl radical.

Indeed, oxygen is well known to slow the degradation of PMMA where it was first noticed by Bresler ${ }^{31}$ et al in 1958 . This has since been explored by a number of chemists including Hirata ${ }^{32}$, Kashiwagi ${ }^{19}$ and Wight ${ }^{33}$ all of whom reported that the presence of oxygen has a stabilizing effect on the degradation of PMMA. Some studies have suggested that oxygen increases the onset of PP and PE degradation. ${ }^{34-36}$ However, it is important to note that these studies were performed at high temperatures using DSC and TGA, which essentially detects initiation of pyrolysis, rather than oxidative propagation. Oxygen diffusion in polymers is slow and it has thus been argued that most degradation actually occurs under inert conditions. ${ }^{37}$ Moreover, for degradation of polyolefins in low $\mathrm{O}_{2}$ environments, mechanical properties, such as tensile strength, fail well before significant oxidation occurs. ${ }^{38}$ This implies propagation is 
occurring via other species, such as $\mathrm{R} \bullet$. In contrast, the mechanical properties of elastomers, for which BAS would be expected to hold, tend to fail in alignment with the degree of oxidation implying reaction with peroxyl radicals is the dominant cause of degradation in those cases. ${ }^{39}$

\section{OTHER OXIDANTS}

Oxygen is not the only oxidant present in our atmosphere and other, more reactive species, such as $\mathrm{O}_{3}, \mathrm{HOO} \bullet, \mathrm{OH} \bullet$ and $\mathrm{NO} \bullet$ are also present in low but nonetheless significant concentrations in our atmosphere. ${ }^{40}$ All are capable of reacting with polymers and many can promote degradation via alternative reaction mechanisms.

Ozone In their studies of polyacrylate degradation, Barner-Kowollik and co-workers ${ }^{20}$ proposed an alternative non-radical mechanism for polymer oxidation at unsaturated end groups involving epoxidation and the subsequent release of formaldehyde and 2-oxopropionic acid alkyl esters. They remarked that whilst it was tempting to blame molecular oxygen as the initiator, other oxidants such as peroxides could instead be responsible..$^{20}$ In subsequent work, we suggested that ozone could instead play that role..$^{41,42}$ Using high-level ab initio calculations, we demonstrated that ozone, for a range of polymers, can initiate bond cleavage and generate reactive RO• and $\mathrm{HOO} \bullet$ radicals that can further propagate degradation (see Scheme 3). Importantly, although tropospheric ozone concentrations reach only $100 \mathrm{ppbv}$, the reactions were fast enough to explain observed degradation rates in their own right. Indeed, the contribution of ozone to the natural weathering of rubber was observed as early as 1952 by Rugg, ${ }^{43}$ and others have observed that ozone accelerates the degradation of saturated ${ }^{44,45}$ and unsaturated ${ }^{46}$ polymers. 


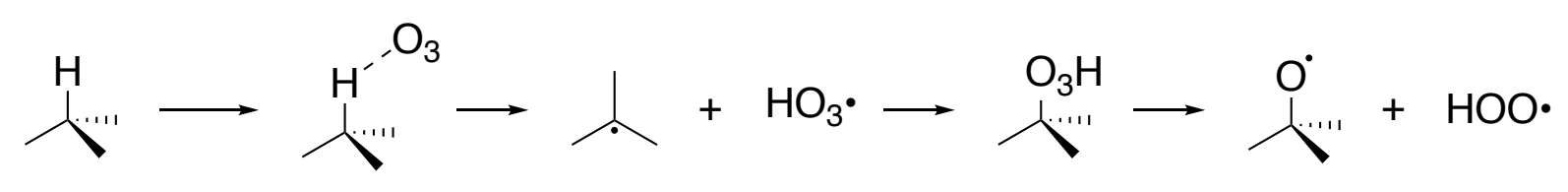

Scheme 3. Initiation of polymer degradation by $\mathrm{O}_{3}$, as proposed in Ref 42 .

HOO• and HO• Much like ozone, hydroperoxyl radicals are also present in small concentrations in the troposphere, along with hydroxyl radicals. They also form when $\mathrm{O}_{3}$ reacts with polymers (Scheme 3). ${ }^{42}$ In 2016, Chen and co-workers proposed that the formation of peroxyl groups in the thermo-oxidation of polyethylene oxide could be explained by $\mathrm{H}$-transfer between $\mathrm{ROO} \bullet$ and $\mathrm{HOO} \bullet$, providing an alternative propagation step to that in the BAS model (see Scheme 4$).{ }^{47}$ For the same polymer, Rabek et al. found that $\mathrm{HO} \bullet$ and $\mathrm{HOO} \bullet$ generated in situ by catalytic decomposition of $\mathrm{H}_{2} \mathrm{O}_{2}$ caused rapid oxidation. ${ }^{48} \mathrm{Hydroxyl}$ radicals, generated in situ, can also contribute to the degradation of polyesters ${ }^{49}$ and polyacrylamides ${ }^{50}$ in solution.

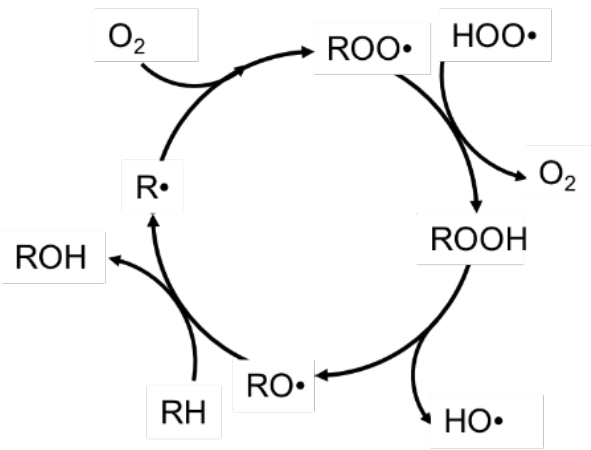

Scheme 4. Alternative propagation step mediated by HOO•, as proposed in Ref 47. 


\section{STUDIES OF POLYMER DEGRADATION PRODUCTS}

The identity of the side-chains and end groups formed during autoxidation has been widely used to gain insight into the mechanism of degradation of polymers. ${ }^{51}$ The propagation step in the BAS mechanism leads to the formation of hydroperoxide species and their existence in the degradation of products of polyolefins such as PE and PP is frequently cited as key evidence for

its validity.${ }^{51-54}$ However, not only can other reaction channels lead to hydroperoxide groups (see Scheme 4), there are complications in their experimental detection. In particular, early studies used a variety of indirect measurements to measure hydroperoxyl species, including colorimetric analysis,${ }^{53}$ titration $^{55}$ or derivatization combined with IR analysis. ${ }^{56}$ These have the disadvantage that the polymer must either be dissolved, swollen or chemically modified, and hence important chemical information may be lost. More recent studies have used FT-IR or NMR for direct monitoring during polymer oxidation. However, while it is possible to observe signals for hydroperoxide species in FT-IR, these signals are relatively small. ${ }^{57}$ While early NMR studies involved the need for samples to be dissolved in solution to have sufficient signal-to-noise, the use of enrichment and labelling and techniques such as 2D NMR and Magic Angle Spinning (MAS) NMR have enabled concentrations of hydroperoxides and a range of other degradation products to be detected and monitored directly. ${ }^{54,58}$ Nonetheless, in ${ }^{13} \mathrm{C}$ NMR there remains a possible ambiguity between the assignment of ROOH at $85.3 \mathrm{ppm}$ and the ROOR' formed from combination reactions, which essentially overlaps. ${ }^{54}$ These can be discriminated by MS studies of labelled ${ }^{32} \mathrm{O}_{2} /{ }^{36} \mathrm{O}_{2}$ systems, ${ }^{59}$ but these checks are rarely carried out.

Notwithstanding these limitations, there is reasonable evidence to suggest that ROOH groups are formed during degradation of saturated polymers. For example, using ${ }^{17} \mathrm{O}$-labelled $\mathrm{O}_{2}$, the 
thermal oxidation of pentacontane was studied via ${ }^{17} \mathrm{O} \mathrm{NMR}$ at $125^{\circ} \mathrm{C}$ and $95^{\circ} \mathrm{C} .{ }^{60}$ Hydroperoxides were observed during the early stages of the oxidation, alongside with a variety of other species. Assink and coworkers carried out a detailed MAS ${ }^{13} \mathrm{C}$ NMR analysis of hydroperoxides in PE after exposure to gamma-radiation in air at 25 and $80^{\circ} \mathrm{C} .{ }^{58}$ At $25^{\circ} \mathrm{C}$ significant quantities of hydroperoxide species were detected but not at $80^{\circ} \mathrm{C}$. It was suggested that the lack of hydroperoxides at the higher temperature is due to their decomposition under the elevated temperature conditions.

If peroxyl termination rather than transfer is expected to occur then this will lead to alcohol formation and/or aldehydes (see Scheme 2). Indeed, the presence of alcohol decomposition products has been confirmed by MS, ${ }^{61} \mathrm{IR},{ }^{56-57}{ }^{17} \mathrm{O} \mathrm{NMR}^{60}$ and ${ }^{13} \mathrm{C}$ NMR studies ${ }^{54,58,62}$ in PE and PP. For example, secondary and tertiary alcohols were found in PP after thermal aging at 50, 80 and $109^{\circ} \mathrm{C}$ and after exposure to $\gamma$-irradiation at 24 and $80{ }^{\circ} \mathrm{C} .{ }^{54}$ Later studies were also carried out on a sample post exposure to gamma-irradiation over a period of 2 years at room temperature as well as at 80,95 and $109^{\circ} \mathrm{C} .{ }^{58}$ Tertiary alcohols were observed in the degradation products at similar or greater concentrations than methyl ketones, in-chain ketones, tertiary carboxylic acids and esters formed from the same tertiary radicals. While the analysis of degradation products is complex, it is clear that the degradation of hydrocarbons leads to a wide range of products, including those consistent with peroxyl termination, and not merely hydroperoxides. 


\section{KINETIC MODELLING}

The ultimate test of the BAS mechanism is its ability to model the kinetics of polymer degradation. However, it is important to keep in mind that the values of the rate coefficients of many of the reactions are themselves typically measured by fitting the same model to experimental data, thus making it difficult to independently assess the model's validity. Nonetheless, used carefully, kinetic studies can be useful in discriminating mechanisms. Indeed, the BAS mechanism was originally developed on the basis of series of kinetic studies of unsaturated hydrocarbons. ${ }^{2-7}$ These showed that the rate of oxidation is first order with respect to the formation of hydroperoxide species, and the rate of oxygen uptake is first order at low oxygen concentrations and zero order at high pressures. The rate of initiation was second order with respect to the concentration of hydroperoxide species, which was proposed to be due to termination taking place between two radicals generated from the decay of the hydroperoxide species. Other observations included the ability of benzoyl peroxide to catalyze oxidation ${ }^{6}$ and quinones to inhibit it, ${ }^{5}$ and quantum yields under UV radiation that were greater than 1 with an initiation rate proportional to the square root of the light intensity. ${ }^{7}$ Together these kinetic observations were concluded to be consistent with autoxidation following the radical chain process in Scheme 1.

The first formal kinetic derivation for the BAS scheme was published by Tobolsky, ${ }^{28}$ using the steady state approximation. Among other things, the linear relationship between the rates of oxygen uptake and peroxyl group formation was derived and then confirmed experimentally for a series of different rubbers at various temperatures. This relationship was later used to test and confirm the applicability of BAS to other polymers, including saturated polymers such as $\mathrm{PP}, 29$ leading to BAS becoming the generally accepted mechanism of autoxidation. In the original 
work by Tobolsky the measurement of rates was limited to oxygen uptake and therefore its ability to predict the formation of degradation products such as hydroperoxides was not tested. However, in 1965 Neiman $^{29}$ reviewed several studies including peroxide analysis, although they were limited to wet chemical techniques that, as explained above, can cause changes to the composition of the degradation products.

Nonetheless, shortcomings in the ability of the BAS model to fit experimental data are apparent. It was noted as early as 1960 that the model is not able to predict the variations between induction times observed in the degradation of many polymers, including saturated polymers such as $\mathrm{PP}{ }^{63}$ It is likely that these differences in induction times were because the rate of oxygen diffusion into polymer samples was important. For example, it was observed that the oxidation of isotactic PP at $130^{\circ} \mathrm{C}$ was primarily dependent on the thickness of the sample tested ${ }^{64}$ In order to reduce the number of model assumptions and to account for the role of oxygen diffusion a number of studies have been done under what has been termed the Closed Loop Scheme (CLS) ${ }^{65}$ The CLS is still fundamentally the BAS model but the initiation step is simplified by making the assumption that all initiation is due to the decomposition of hydroperoxide species. Subsequent improvements included parameters and relationships to account for oxygen solubility ${ }^{66}$ and diffusion ${ }^{67}$ within polymer samples. The model has also been expanded to incorporate the chain scission, branching and cross linking in order to predict molecular weight of the degraded polymer. ${ }^{55,67}$ Studies have been performed for the thermal and photo-thermal oxidation of PP at temperatures of 45,60 and $80^{\circ} \mathrm{C}$. The degradation of molecular weight ${ }^{67}$ as well as the production of degradation species including hydroperoxides was fitted to the model rate parameters. Adequate fits were attained for changes in molecular weights, but the model over estimates the rate of production of hydroperoxides, particularly at higher temperatures.$^{55}$ 
The above modifications do not alter the basic propagation mechanism in BAS, or even allow for its reversibility (which, given its strongly endothermic nature, is problematic). However, a small number of studies have considered more fundamental changes to the mechanism of degradation. For example, Chen et al ${ }^{47}$ developed a model based on the $\mathrm{HOO} \bullet$ mediated degradation mechanism shown in Scheme 4. They examined the formation of hydroperoxide species at $200^{\circ} \mathrm{C}$ in polyethylene oxide by examining the product profiles and have proposed a detailed mechanism to fit this profile. They found that the fitted rate constant for reaction of $\mathrm{HOO} \bullet$ with ROO• was almost ten orders of magnitude greater than that for the abstraction of a hydrogen from the polymer chain by ROO . However, as in the BAS modelling studies, these parameters were indirectly estimated by fitting the model to the experimental data.

Kinetic modelling studies based on fitting models to data have limitations as the adjustable parameters make it possible for many models to fit the same data, irrespective of the validity of their underlying assumptions. An alternative approach, is to obtain the rate parameters independently either from more direct measurement techniques (such as laser flash photolysis) or from accurate quantum chemical calculations. In that way, model predictions that can be compared directly with experimental data without fitting, and, provided their rate coefficients are accurate, any number of potential reaction channels can be added without compromising the model. Thus, all conceivable reaction channels can be included (see Scheme 5), and their kinetic relevance can then be assessed as a function of reaction conditions. Studies in this direction are currently underway. 


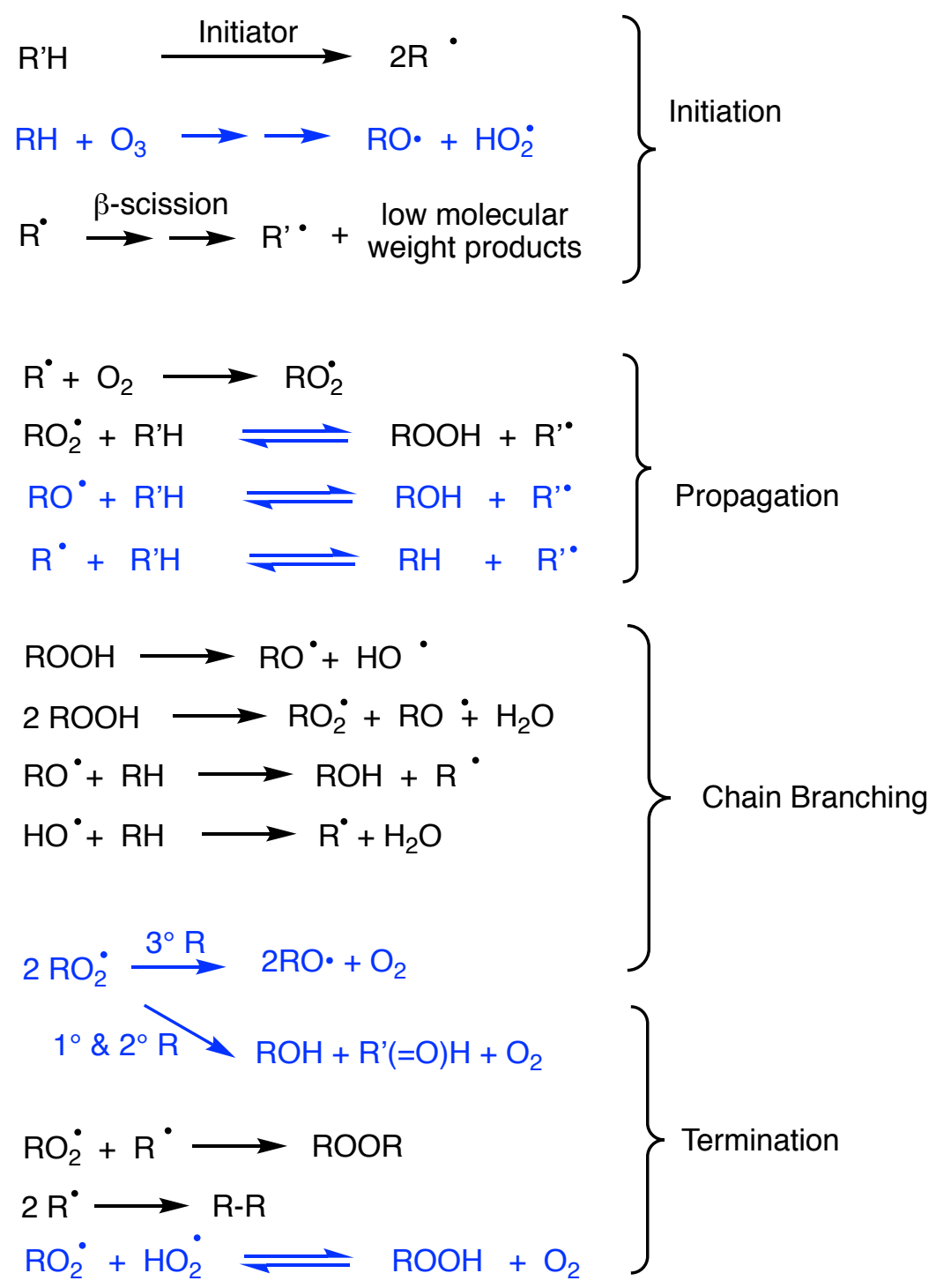

Scheme 5. A more complete autoxidation scheme. Added reaction channels are shown in blue.

\section{CONCLUSIONS}

The textbook model for autoxidation assumes that degradation is propagated from one polymer chain to another via hydrogen atom abstraction by a peroxyl radical. Yet this reaction is strongly thermodynamically disfavored for most polymer classes. The reverse reaction is thus many orders of magnitude faster than the forward reaction but is not even included in the kinetic model. Nevertheless, autoxidation certainly occurs. The formation of hydroperoxide functional 
groups due to this transfer reaction, and its first order dependence on $\mathrm{O}_{2}$, has been widely cited as evidence for the scheme. In this review we have dissected the literature in an attempt to resolve these apparent contradictions.

While much of the evidence for hydroperoxide groups in the degradation products of saturated polymers is based on analysis techniques that are open to debate, due to overlapping signals or extreme oxidation conditions, it is hard to rule out the formation of hydroperoxides. At the same time, a plethora of other degradation products are formed, more in-line with the consequences of peroxyl termination. This suggests that peroxyl termination is at least competitive with transfer in saturated polymers, if not dominant. Plausible mechanisms involving other atmospheric oxidants also exist for hydroperoxide formation. Hence hydroperoxide formation alone is not enough to validate the BAS mechanism.

Likewise, the role of oxygen in degradation is also more complex than it first appears. Studies of saturated polymers show that in low oxygen environments polymer degradation is a lot faster than polymer oxidation. For unsaturated polymers, where peroxyl transfer is more facile, these rates follow each other closely. This implies that for saturated polymers, polymer degradation may be inhibited to some extent by the formation of unreactive peroxyl radicals, and that hydrogen atom transfer by carbon-centered radicals provides a viable alternative path for propagating degradation. There is solid evidence that degradation is accelerated by the presence of unsaturated groups, and hence the unfavourability of peroxyl transfer for saturated polymers does lead to slower degradation.

Drawing together these observations, clearly there are viable alternatives to the BAS mechanism that do not involve the unfavorable peroxyl transfer step. While thorough kinetic studies are 
needed to assess the relative contribution of the different channels under realistic conditions, it is clear from the current literature that unsaturated groups and quaternary units compromise the stability of polymers. These should thus be avoided where possible, or conversely incorporated when degradable materials are required. Moreover, for saturated polymers, oxygen has a protective effect on degradation, and other atmospheric oxidants such as $\mathrm{O}_{3}$ and $\mathrm{HOO} \bullet$ are likely to be key culprits in the degradation of materials in polluted urban environments, suggesting that antiozonants and other such measures should contribute to polymer stabilization.

\section{AUTHOR INFORMATION}

\section{Corresponding Author}

*Email: michelle.coote@anu.edu.au

\section{Author Contributions}

$\ddagger$ These authors contributed equally.

\section{Notes}

The authors declare no competing financial interest.

\section{Notes}

Leesa Smith completed a PhD in Industrial Chemistry in 2001 and has worked in several in industry positions prior to commencing employment at ANU as a research officer.

Heather Aitken received her BSc in 2009 and MSc (Distinction) in 2011 from the University of Melbourne. She began her PhD studies in 2017 at the Australian National University with Prof. Michelle Coote. 
Michelle Coote received her PhD in 2000 from the University of NSW. After postdoctoral work at the University of Durham, UK, she joined the Australian National University in 2001, initially as a postdoctoral fellow. She became a full Professor in 2010, was elected to the Australian Academy of Science in 2014 and is currently an ARC Laureate Fellow and an Associate Editor of J. Am. Chem. Soc.

\section{ACKNOWLEDGMENT}

MLC gratefully acknowledges the Australian Research Council (ARC) for a Georgina Sweet ARC Laureate Fellowship, and Dr Anya Gryn'ova, Dr Richmond Lee and Professor Françoise Reyniers for many stimulating discussions about autoxidation mechanisms.

\section{REFERENCES}

${ }^{1}$ Laycock, B.; Nikolic, M., Colwell, J. M.; Gauthier, E.; Halley, P., Bottle, S., George, G., Lifetime prediction of biodegradable polymers. Prog. Polym. Sci. 2017, 71, 144-189.

${ }^{2}$ Bolland, J.L., Kinetic studies in the chemistry of rubber and related materials. I. The thermal oxidation of ethyl linoleate. Proc R Soc Lon Ser. A 1946, 186, 218-236.

${ }^{3}$ Bolland J.L.; Gee, G., Kinetic studies in the chemistry of rubber and related materials. II. The kinetics of oxidation of unconjugated olefins. Trans. Faraday Soc. 1946, 42, 236-243.

${ }^{4}$ Bolland, J.L.; Gee, G., Kinetic studies in the chemistry of rubber and related materials. III. Thermochemistry and mechanisms of olefin oxidation. Trans. Faraday Soc. 1946, 42, 244-252. 
${ }^{5}$ Bolland, J.L.; Tenhave, P., Kinetic studies in the chemistry of rubber and related materials. IV. The inhibitory effect of hydroquinone on the thermal oxidation of ethyl linoleate. Trans. Faraday Soc. 1947, 43, 201-210.

${ }^{6}$ Bolland, J.L., Kinetic studies in the chemistry of rubber and related materials. VI. The benzoyl peroxide-catalysed oxidation of ethyl linoleate, Trans. Faraday Soc., 1948, 44, 669-677.

${ }^{7}$ Bateman, L., Gee, G., A kinetic investigation of the photochemical oxidation of certain nonconjugated olefins, Proc. Roy. Soc. A, 1948, 195, 376-391.

${ }^{8}$ Yin, H.; Xu, L.; Porter, N.A., Free Radical Lipid Peroxidation: Mechanisms and Analysis. Chem. Rev. 2011, 111, 5944-5972.

${ }^{9}$ Audouin, L.; Achimsky, L.; Verdu, J, in Handbook of Polymer Degradation, Ed. Hamid, S.H., Marcel Dekker, New York, 2nd Edn, 2000, 727-763.

10 Zweifel, H.; Maier, R.D.; Schiller, M., Plastics Additives Handbook, Carl Hanser Verlag, Munich, 6th Edn, 2009, 4-6.

${ }^{11}$ Gryn'ova, G.; Hodgson, J.L.; Coote, M.L., Revising the mechanism of polymer autooxidation. Org. Biomol. Chem. 2011, 9, 480-490.

${ }^{12}$ Lee, R.; Gryn’ova, G.; Ingold, K.U.; Coote, M.L., Why are sec-Alkylperoxyl Bimolecular Self-Reactions Orders of Magnitude Faster than the Analogous Reactions of tert-Alkylperoxyls? The Unanticipated Role of CH Hydrogen Bond Donation. Phys. Chem. Chem. Phys. 2016, 18, $23673-23679$. 
${ }^{13}$ Starnes Jr, W.H., Structural and mechanistic aspects of the thermal degradation of poly(vinyl chloride), Prog. Polym. Sci. 2002 27, 2133-2170.

14 Kelsey, D.T.; Kiibler, K.S.; Tutunjian, P.N., Thermal stability of poly(trimethylene terephthalate) Polymer 2005, 46, 8937-8946.

${ }^{15}$ Nakatani, H.; Kurniawan, D.; Taniike, T.; Terano, M. Degradation behaviour of polymer blend of isotactic polypropylenes with and without unsaturated chain end group. Sci. Technol. Adv. Mater., 2008, 9, 024401.

${ }^{16}$ Allen, N.S.; Edge, M.; Holdsworth, D.; Rahman, A.; Catalina, F.; Fontan, E.; Escalona, A.M.; Sibon, F.F. Ageing and Spectroscopic Properties of Polyethylenes: Comparison with Metallocene Polymer. Polym. Degrad. Stab., 2000, 67, 57-67.

${ }^{17}$ Chirinos-Padron, A.J.; Hernandez, P.H.; Chavez, E.; Allen, N.S.; Vasiliou, C.; DePoortere M. Influences of Unsaturation and Metal Impurities on the Oxidative Degradation of High Density Polyethylene. Eur. Polym. J., 1987, 23, 935-940.

${ }^{18}$ Pazur, R.J.; Petrov, I. The thermo-oxidation of isoprene containing copolymers of isobutylene: Activation energies and reactions from room temperature to $100^{\circ}$ C. Polym. Degrad. Stab. 2015, $113,55-65$.

${ }^{19}$ Kashiwagi, T.; Inaba, A.; Brown, J.E.; Hatada, K.; Kitayama, T.; Masuda E. Effects of Weak Linkages on the Thermal and Oxidative Degradation of Poly(methyl methacrylates). Macromolecules, 1986, 19, 2160-2168. 
${ }^{20}$ Bennet, F.; Lovestead, T.M.; Barker, P.J.; Davis, T.P.; Stenzel, M.H.; Barner-Kowollik, C. Degradation of Poly(methyl methacrylate) Model Compounds at Constant Elevated Temperature Studied via High Resolution Ionization Mass Spectrometry (ESI-MS). Macromol. Rapid Commun. 2007, 28, 1593-1600.

21 Hillemans, J.P.H.M.; Colemonts, C.M.C.; Meier, R.J.; Kip B.J.; An in situ Raman spectroscopic study of the degradation of PVC. Polym. Degrad. Stab. 1993, 42, 323-333.

${ }^{22}$ Gardette, J.C.; Lemaire, J.; Photothermal and Thermal Oxidations of Rigid, Plasticized and Pigmented Poly(vinyl chloride). Polym. Degrad. Stab., 1991, 135-167.

${ }^{23}$ Soeriyadi, A.H.; Trouillet, V.; Bennet, F.; Bruns, M.; Whittaker, M.R.; Boyer, C.; Barker, P.J.; Davis, T.P.; Barner-Kowollik, C. A Detailed Surface Analytical Study of Degradation Processes in (Meth)acrylic Polymers. J. Polym. Sci., A: Polym. Chem. 2012, 50, 1801-1811.

${ }^{24}$ Gardette, M.; Perthue, A.; Gardette, J-L.; Janecska, T.; Földes, E.; Pukánszky, B.; Therias, S. Photo- and thermal-oxidation of polyethylene: Comparison of mechanisms and influence of unsaturation content. Polym. Degrad. Stab. 2013, 98, 2383-2390.

${ }^{25}$ Pazur, R.J. Activation energy of poly(isobutylene) under thermo-oxidative conditions from 40-100C. Polym. Degrad. Stab., 2014, 104, 57-61.

26 Gonon, L.; Troquet, M.; Fanton, E.; Gardette, J. Thermo- and Photo-oxidation of Polyisobutylene. II. Influence of temperature. Polym. Degrad. Stab., 1998, 62, 541-549. 
${ }^{27}$ Hawkins, W.H.; Matreyek, W.; Winslow, F.H. The morphology of semicrystalline polymers. Part I. The effect of temperature on the oxidation of polyolefins. J. Polym. Sci., A: Polym. Chem. 1959, $41,1-11$.

${ }^{28}$ Tobolsky, A.V.; Metz, D.J.; Mesrobian, R.B., Low temperature autoxidation of hydrocarbons: the phenomenon of maximum rates, J. Am. Chem. Soc. 1950, 72, 1942-1952.

${ }^{29}$ Neiman, M.B., Mechanism of the Oxidative Thermal Degradation and of the Stabilization of Polymers, Russ. Chem. Rev., 1964, 33, 13-27.

${ }^{30}$ Denisov, Y.T.; Vol'pert, A.I.; Flipenko, V.P.; Diffusion Regime of the Auto-oxidation of Polymers. Polymer Science U.S.S.R.; 1986, 28, 2314-2322.

31 Bresler, S.E.; Os'minskaya, A.T.; Popov, A.G.; Saminskii, E.M.; Frenkel, S.Y. Heat destruction of poly(methyl methacrylate). Kolloidnyi Zhurnal, 1958, 20, 403-430.

${ }^{32}$ Hirata T.; Kashiwagi, T.; Brown J.E.; Thermal and oxidative degradation of poly(methyl methacrylate): weight loss. Macromolecules, 1985, 18, 1410-1418.

${ }^{33}$ Peterson, J.D.; Vyazovkin, S.; Wight, C.A. Kinetic Study of Stabilizing Effect of Oxygen on Thermal Degradation of Poly(methyl methacrylate). J. Phys. Chem. B, 1999, 103, 8087-8092.

${ }^{34}$ Gallo, R.; Severini, F. Reactivity of weathered polyolefinic samples studied by means of TGA. Polym. Degrad. Stab. 2017, 143, 231-238. 
${ }^{35}$ Peterson, J.D.; Vyazovkin, S.; Wight, C.A. Kinetics of the Thermal and Thermo-Oxidative Degradation of Polystyrene, Polyethylene and Poly(propylene). Macromol. Chem. Phys., 2001, $202,775-784$

${ }^{36}$ Cuadri, A.A.; Martín-Alfonso, J.E. The effect of thermal and thermo-oxidative degradation conditions on rheological, chemical and thermal properties of HDPE. Polym. Degrad. Stab. 2017, $141,11-18$.

${ }^{37}$ Celina, M.C. Review of Polymer Oxidation and its Relationship with Materials Performance and Lifetime Prediction. Polym. Degrad. Stab. 2013, 98, 2419-2429.

${ }^{38}$ Fayolle, B.; Audouin, L.; Verdu, J. Oxidation induced embrittlement in polypropylene - a tensile testing study. Polym. Degrad. Stab. 2000, 70, 333-340.

${ }^{39}$ Celina, M.; Wise, J.; Ottesen DK.; Gillen, KT.; Clough, R.L. Correlation of chemical and mechanical property changes during oxidative degradation of neoprene. Polym. Degrad. Stab. 2000, 68, 171-184.

40 Stone, D.; Whalley, L.K.; Heard, D.W. Tropospheric $\mathrm{OH}$ and $\mathrm{HO} 2$ radicals: field measurements and model comparisons. Chem. Soc. Rev., 2012, 41, 6348-6404.

${ }^{41}$ Lee, R., Coote ,M.L. New insights into 1,2,4-trioxolane stability and the crucial role of ozone in promoting polymer degradation Phys. Chem. Chem. Phys. 2013, 15, 16428-16431.

${ }^{42}$ Lee, R; Coote, M.L.; Mechanistic insights into ozone-initiated oxidative degradation of saturated hydrocarbons and polymers Phys. Chem. Chem. Phys., 2016 18, 24663-24671. 
${ }^{43}$ Rugg, J.S.; Ozone Crack Depth Analysis for Rubber. Anal. Chem., 1952, 24, 818-821.

${ }^{44}$ Cataldo, F.; Ricci, G.; Crescenzi, V. Ozonization of atactic and tactic polymers having vinyl, methylvinyl and dimethylvinyl pendant groups. Polym. Degrad. Stab., 2000, 67, 421-426.

${ }^{45}$ Razumovsky, S.D.; Podmasteriyev, V.V.; Zaikov, G. Kinetics of the Growth of Cracks on Polyisoprene Vulcanizates in Ozone. Polym. Degrad. Stab., 1986, 16, 317-324.

${ }^{46}$ Popov, A.A.; Blinov, N.N; Krisyuk, B. E.; Karpova, S.G.; Peverov, A.N.; Zaikov, G. Y. Oxidative Degredation of Polymers Under Load. Ozone-Oxygen Action on Oriented Polyethylene. Polymer Science U.S.S.R., 1981, 23, 1666-1674.

${ }^{47}$ Chen, L., Yamane, S, Sago, T., Hagihara, H., Kutsuna, S., Uchimaru, T., Suda, H., Sato, H., Mizukado, J., Experimental and modeling approaches for the formation of hydroperoxide during the auto-oxidation of polymers: Thermal-oxidative degradation of polyethylene oxide, Chem. Phys. Lett. 2016, 657, 83-89.

${ }^{48}$ Kaczmarek, H.; Lindén, L.Å.; Rabek, J.F. Reactions of Hydroxyl (HO·) and Hydroperoxyl $\left(\mathrm{HO}_{2}{ }^{\circ}\right)$ radicals generated chemically and photochemically with poly(ethylene oxide). J. Polym. Sci., A: Polym. Chem. 1995, 33, 879-890.

${ }^{49}$ Ali, S.A.M.; Zhong, S.-P.; Doherty, P.J.; Williams, D.F. Mechanisms of Polymer Degradation in Implantable Devices: I. Poly(caprolactone). Biomaterials, 1993, 14, 648-656. 
${ }^{50}$ Ramsden, D.K.; McKay, K. Degradation of polyacrylamide in aqueous solution induced by chemically generated hydroxyl radicals: Part I - Fenton's reagent. Polym. Degrad. Stab., 1986, $14,217-229$.

${ }^{51}$ Vasile, C., Handbook of Polyolefins, $2^{\text {nd }}$ Edition, 2000, Marcel Dekker, Inc., New York, Basel.

52 Gugumus, F., Re-examination of the role of hydroperoxides in polyethylene and polypropylene: chemical and physical aspects of hydroperoxides in polyethylene, Polym. Degrad. Stab., 1995, 49, 29-50.

${ }^{53}$ Carlsson D.J., Lacoste J., A critical comparison of methods for hydroperoxide measurement in oxidized polyolefins. Polym. Degrad. Stab. 1991, 32, 377-386.

${ }^{54}$ Mowery, D.M., Assink, R.A., Derzon, D.K., Klamo, S.B., Clough, R.L., Bernstein, R., SolidState ${ }^{13} \mathrm{C}$ NMR Investigation of the Oxidative Degradation of Selectively Labeled Polypropylene by Thermal Aging and $\gamma$-Irradiation, Macromolecules 2005, 38, 5035-5046.

${ }^{55}$ Francois-Heude, A., Richaud, E., Desnoux, E, Colin, X., A general kinetic model for the photothermal oxidation of polypropylene, J. Photochem. Photobiol. A: Chem. 2015, 296, 48-65.

${ }^{56}$ Lacoste, J., Carlsson, D.J., Gamma-, Photo-, and Thermally-Initiated Oxidation of Linear Low-Density Polyethylene: A Quantitative Comparison of Oxidation Products, J. Polym. Sci., A: Polym. Chem. 1992, 30, 493-500.

57 Lacoste, J., Carlsson, D.J., Falicki, S., Wiles, D.M., Polyethylene Hydroperoxide Decomposition Products, Polym. Degrad. Stab. 1991, 34, 309-323. 
${ }^{58}$ Assink, R.A., Celina, M., Dunbar, T.D., Alam, T.M., Clough, R.L., Gillen, K.T., Analysis of Hydroperoxides in Solid Polyethylene by MAS ${ }^{13} \mathrm{C}$ NMR and EPR, Macromolecules 2000, 33, 4023-4029.

${ }^{59}$ Philippart, J.L, Gardette, J.L., Thermo-oxidation of isotactic polypropylene in ${ }^{32} \mathrm{O}_{2}-{ }^{36} \mathrm{O}_{2}$ : comparison of the mechanisms of thermo- and photo-oxidation, Polym. Degrad. Stab. 2001, 73, 185-187.

${ }^{60}$ Alam, T.M., Celina, M., Assink, R.A., Clough, R.L., Gillen, K.T., Wheeler, D.R., Investigation of Oxidative Degradation in Polymers Using ${ }^{17} \mathrm{O}$ NMR Spectroscopy, Macromolecules 2000, 33, 1181-1190.

${ }^{61}$ Thornberg, S.M., Bernstein, R., Mowery, D.M., Klamo, S.B., Hochrein, J.M., Brown, J.R., Derzon, D.K., Clough, R.L., Insights into Oxidation Pathways, from Gaseous Products of Polypropylene with Selective Isotopic Labeling, Macromolecules 2006, 39, 5592-5594.

${ }^{62}$ Jelinski, L.W., Dumais, J.J.; Luongo, J.P., Cholli, A.L., Thermal oxidation and its analysis at low levels in polyethylene, Macromolecules, 1984, 17, 1650-1655.

${ }^{63}$ Bresler, S.E., Os'minskala, A.T., Popv, A.G., The Thermal Degradation of Stereoregular Polypropylene, Vysokol. Soedin., 1960, 2, 130-132.

${ }^{64}$ Russell, C.A., Pascale, J.V., The early stages of isotactic polypropylene oxidation, J. Appl. Polym. Sci., 1963, 7, 959-969. 
${ }^{65}$ Audouin, L., Gueguen, V., Tcharkhtchi, A., Verdu, J., “Close loop” mechanistic schemes for hydrocarbon polymer oxidation J. Polym. Sci. A. 1995, 33, 1921-1927.

${ }^{66}$ François-Heude, A., Richaud, E., Guinault, A., Desnoux , E., Colin, X., Impact of Oxygen Transport Properties on Polypropylene Thermal Oxidation, Part 1: Effect of Oxygen Solubility, $J$. Appl. Polym. Sci., 2015, 132, 41441.

67 François-Heude, A., Richaud, E.,Guinault, A., Desnoux, E., Colin, X., Impact of Oxygen Transport Properties on Polypropylene Thermal Oxidation, Part II: Effect of Oxygen Diffusivity, J. Appl. Polym. Sci. 2015, 132, 41562. 